\title{
Comparative transcriptomic analysis reveals gene regulation mediated by caspase activity in a chordate organism
}

\author{
Gabriel Krasovec ${ }^{1,2^{*}}$, Anthi Karaiskou ${ }^{3}$, Éric Quéinnec ${ }^{1}$ and Jean-Philippe Chambon ${ }^{4}$
}

\begin{abstract}
Background: Apoptosis is a caspase regulated cell death present in all metazoans defined by a conserved set of morphological features. A well-described function of apoptosis is the removal of excessive cells during development and homeostasis. Recent studies have shown an unexpected signalling property of apoptotic cells, affecting cell fate and/or behaviour of neighbouring cells. In contrast to the apoptotic function of cell elimination, this new role of apoptosis is not well understood but seems caspase-dependent. To deepen our understanding of apoptotic functions, it is necessary to work on a biological model with a predictable apoptosis pattern affecting cell fate and/or behaviour. The tunicate Ciona intestinalis has a bi-phasic life cycle with swimming larvae which undergo metamorphosis after settlement. Previously, we have shown that the tail regression step during metamorphosis, characterized by a predictable polarized apoptotic wave, ensures elimination of most tail cells and controls primordial germ cells survival and migration.

Results: We performed differential transcriptomic analysis between control metamorphosing larvae and larvae treated with the pan-caspase inhibitor Z-VAD-fmk in order to explore the transcriptional control of apoptotic cells on neighbouring cells that survive and migrate. When caspase activity was impaired, genes known to be involved in metamorphosis were downregulated along with other implicated in cell migration and survival molecular pathways.
\end{abstract}

Conclusion: We propose these results as a confirmation that apoptotic cells can control surrounding cells fate and as a reference database to explore novel apoptotic functions in animals, including those related to migration and differentiation.

Keywords: Comparative transcriptomics, Caspases, Apoptosis, Metamorphosis, Migration, Ascidians

\section{Background}

Apoptosis is a regulated cell death defined by morphological features and depending on caspases [1-3]. Being ubiquitous in metazoans [4-7], the main function of apoptosis is the elimination of unwanted cells [8], such as the interdigital tissues during embryogenesis of

\footnotetext{
* Correspondence: gabriel.krasovec@nuigalway.ie

${ }^{1}$ Institut de Systématique, Evolution, Biodiversité (ISYEB), UMR 7205,

Sorbonne Université, Muséum National d'histoire Naturelle, CNRS, EPHE, 7

Quai St-Bernard, F-75252 Paris Cedex 05, France

${ }^{2}$ Center for Chromosome Biology, School of Natural Sciences, National University of Ireland Galway, Galway, Ireland

Full list of author information is available at the end of the article
}

tetrapods [9] or larval tissues during metamorphosis of many animals [10]. Apoptosis is also implicated in homoeostasis by fine-tuning the balance between cell death and proliferation like in gonad size control in rodents [11].

While the function of cell elimination by apoptosis is highly documented, apoptosis seems to have a broader morphogenetic function that goes beyond cells elimination. Accumulating evidence in many metazoans suggest that apoptotic cells can emit caspase-dependent signals to their neighbours, modulating their fate (survival/death, differentiation or proliferation) or behaviour (migration) [12, 13]. Apoptotic-induced proliferation was

(c) The Author(s). 2021 Open Access This article is licensed under a Creative Commons Attribution 4.0 International License, which permits use, sharing, adaptation, distribution and reproduction in any medium or format, as long as you give appropriate credit to the original author(s) and the source, provide a link to the Creative Commons licence, and indicate if changes were made. The images or other third party material in this article are included in the article's Creative Commons licence, unless indicated otherwise in a credit line to the material. If material is not included in the article's Creative Commons licence and your intended use is not permitted by statutory regulation or exceeds the permitted use, you will need to obtain permission directly from the copyright holder. To view a copy of this licence, visit http://creativecommons.org/licenses/by/4.0/ The Creative Commons Public Domain Dedication waiver (http://creativecommons.org/publicdomain/zero/1.0/) applies to the data made available in this article, unless otherwise stated in a credit line to the data. 
reported in several organisms, such as in the cnidarian Hydra, where apoptosis promotes proliferation of adjacent cells through emission of Wnt3 signalling in a caspasedependant manner during head regeneration [14]. Similar observations have been made during rodent liver regeneration, where cleavage of iPLA2 by caspases in apoptotic cells led to proliferation of adjacent cells [15]. Apoptotic cells can also induce differentiation, as was reported during the metamorphosis of the cnidarian Hydractinia echinata [16]. Finally, apoptotic cells modulate death or survival balance, as was observed in the Drosophila imaginal disc, by producing the Tie ligand Pvf1, that induces death resistance of neighbouring cells [17]. Apoptoticdependent migration is well described in mammals, in which apoptotic cells secrete directional signals such as Lysophophatidylcholine or Sphingosine-1-Phosphate, promoting migration of leukocytes [18, 19]. Furthermore, in Xenopus laevis tadpole, an apoptotic-dependent axon guidance was suggested during tail regeneration after injury [20].

While caspase-dependent signals emitted by apoptotic cells start to be characterised, almost no target genes are identified in receptor cells. Evaluating the capacity of caspases to affect gene expression and influence fate and/or behaviour of cells adjacent to apoptosis is the first fundamental step to better characterise this new function in animals.

In this report, we took advantage of the predictable spatiotemporal apoptotic profile of ascidians [21, 22], in particular during the Ciona intestinalis metamorphosis, which is concomitant with cell survival and cell migration [21, 23, 24]. Ciona belongs to the Urochordata, the sister group of vertebrates [25], and has a biphasic life cycle composed of a pelagic larva and a benthic adult. Embryogenesis generates a tadpole-like swimming larva consisting of an anterior trunk and a posterior tail which, after few hours of swimming, settles and metamorphoses into a sessile juvenile. A hallmark of metamorphosis is the apoptotic-dependent tail regression [21] during which apoptosis starts at the tip of the tail and propagates toward the trunk, making it easily anticipated; a unique feature among chordates. Using TUNEL labelling and electron microscopy, we previously described in detail this apoptotic profile. Apoptosis starts in epidermal cells at the most posterior tail tip, then, it affects the notochord cells and the striated muscle cells in a postero-anterior wave. The tunic cells are also randomly affected. On the opposite, two tissues survive and migrate during, or prior to, tail regression; the ventral endodermal strand and the eight primordial germ cells (PGC) [23, 24, 26]. PGC, located at the postero-ventral side of the tail tip, escape from cell death by moving toward the trunk, and are consequently surrounded by apoptotic cells during the tail regression. Interestingly, we previously demonstrated that the pan-caspase inhibitor Z-VAD-Fmk blocks both apoptotic dependent-tail regression and PGC migration, suggesting that PGC migration is regulated by apoptotic cells [23].

To identify genes controlled by caspases activity during tail regression, we performed a comparative transcriptomic analysis at the beginning and at mid-tail regression between control metamorphosing larvae or larvae exposed to the pan-caspase inhibitor Z-VAD-fmk, already successfully used in Ciona [21] (Fig. S1). Based on a de novo transcriptome, we identified 61 genes differentially expressed between the beginning and mid-tail regression in control larvae. Next, we found 65 genes differentially expressed between control and treated larvae (21 and 44 at the beginning and at mid-tail regression, respectively). Interestingly, misregulation of some genes upon caspase inhibition was reported during ascidian metamorphosis, but also reported in cell survival and cell migration in several animals [27-30]. Our results offer a first database of genes transcriptionally modulated by apoptosis during a dynamic morphogenetic process in a chordate, allowing exploration of novel apoptotic functions in animals.

\section{Results}

\section{Genes differentially express between the onset and the} mid-tail regression

Globally, the robustness of our analysis is shown by a heat map allowed visualization of result congruence between replicates (Fig. 1). To confirm relevance of our data, we randomly chose 6 genes differentially expressed in our transcriptomic analysis to performed real-time PCR (Fig. 2A). Five of them exhibited an expression profile that was similar for both experiments.

One of them, KH.C7.314, is less expressed at the midtail regression in comparison to the beginning of the process in control larvae in our transcriptomic analysis. Similar profile was observed with real-time PCR, but the difference is less pronounced and not statistically significant. Despite this, control by real-time PCR globally validated our transcriptomic data.

First, we have focused on genes differentially expressed in control metamorphosing larvae between the beginning and the mid-tail regression. Twenty-five genes (41\%) were up-regulated from the beginning to the midtail regression with the strongest increase recorded for KH.C9.385 (smyd3) (Table 1). Conversely, 36 genes (59\%) show decreased expression, with a subset of genes whose expression was no longer detectable such as KH.14.261 (lysozyme-like) (Table 2). Among these identified genes, several were already reported during a previous cDNA chip analysis of Ciona metamorphosis, such as KH.C7.314 (MED30), KH.C11.274 (p-selectin, known as Ci-sushi) which is expressed in almost all the tail, or 
A

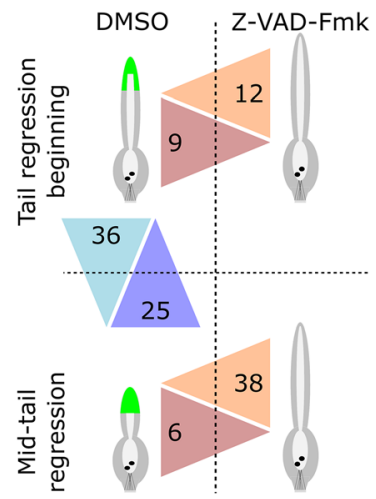

Genes up-regulated at mid-tail regression Genes down-regulated at mid-tail regression Genes up-regulated by the Z-VAD Genes down-regulated by the Z-VAD Apoptosis

B

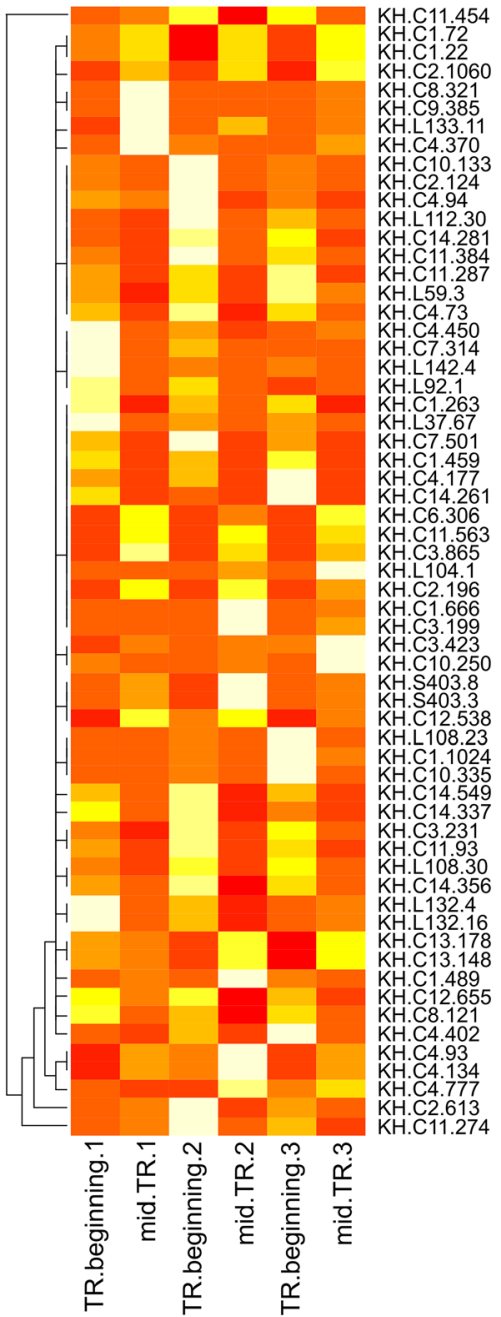

C

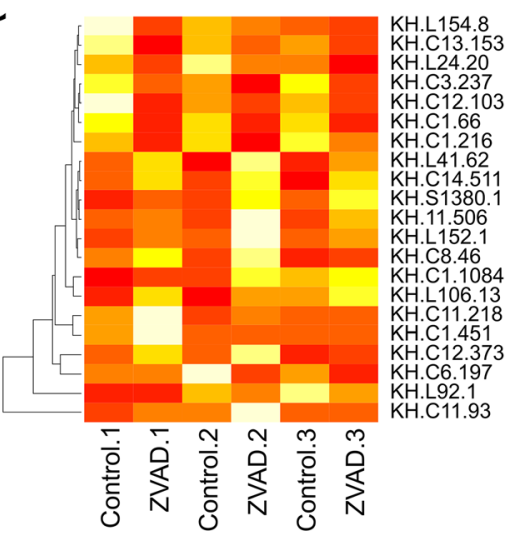

D

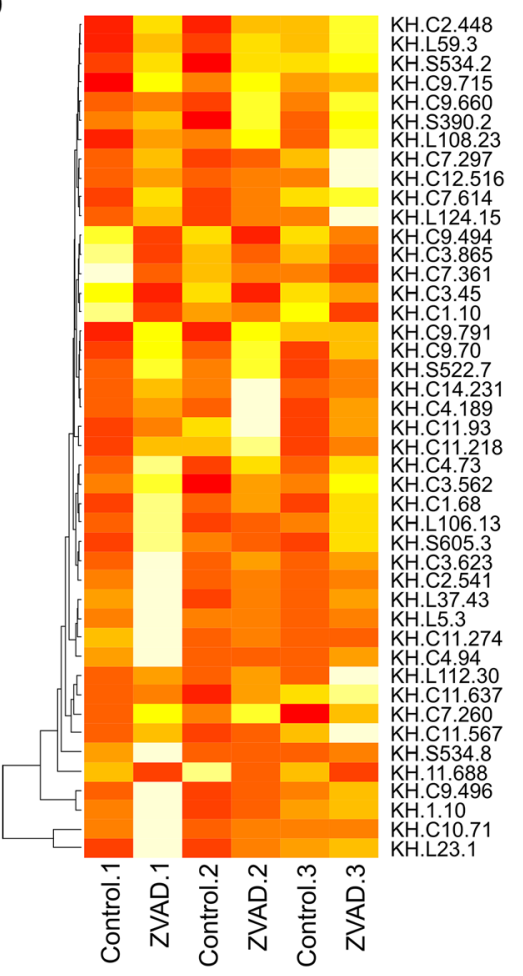

Gene expression ratio

Fig. 1 (See legend on next page.) 
(See figure on previous page.)

Fig. 1 A, Counting of genes differentially expressed between conditions. B, Heatmaps showing genes differentially expressed in control between the beginning of tail regression (TR) and the mid-regression. $\mathbf{C}$, Heatmaps showing genes diffenrentially expressed at the beginning of tail regression between control and Z-VAD-fmk treated larvae. D, Heatmaps showing genes diffenrentially expressed at mid-regression between control and Z-VAD-fmk treated larvae

KH.L132.4 (matrilin-2) expressed in epidermal cells at the tip of the tail in premetamorphic larva (Fig. 2B) [29]. In addition, some of the genes identified by our screen had already been detected by substantial RNA sequencing data coupled with in situ hybridization data available on ANISEED database (http://www.aniseed.cnrs.fr). For example, KH.L132.16 (fibrillin-3) starts to be expressed at mid-neurulae with a maximum expression in larva, in which it is detected in all the epidermis including the tail. Furhermore, KH.C10.250 (fox-1, RNAbinding) is expressed in tail muscle at mid-tailbud stage to become ubiquitous in larva [31].

We also observed that some among these were also impacted by Z-VAD-fmk treatment (Tables 3, 4, 5 and 6) such as KH.C6.197 (meta2), KH.C1.10 (LIM), KH.C1.216 (myosin light chain 3), and KH.C11.274 (Ci-sushi) [27-30]. The detection of genes already known to be expressed in the tail and involved in tail regression (i.e. Ci-sushi, Ci-meta2) is consistent with previous studies on ascidians metamorphosis, validates our experimental procedures and supports the relevance of our database.

\section{Caspase inhibition affects gene expression during the tail regression}

In total, 65 genes were affected by the inhibition of caspases during Ciona tail regression (Fig. 1). At the beginning of tail regression 12 genes were upregulated by the Z-VAD-fmk treatment (so negatively regulated by caspase activity in physiological conditions) with the greatest expression increase observed for KH.C11.506 (girdin) and KH.S1380.1 (mucin-5 AC) (Table 3), and 9 genes were downregulated (so positively regulated by caspase activity) with extreme effects on KH.C1.66, which is no longer expressed (Table 4).

At mid-tail regression, we identified 38 upregulated genes in the Z-VAD-fmk condition with the highest increase noted for KH.C12.516 (Table 5), and 6 downregulated genes (Table 6) with strongest effect concerning KH.C1.910.

\section{Transcription is necessary for the PGCs migration}

We previously demonstrated that Z-VAD-fmk blocked both tail regression and PGC migration, and that apoptotic wave propagation and PGC migration speed were correlated [23]. Here, we show that transcription is necessary for PGC survival and migration (Fig. 3). We exposed metamorphosing larvae to the transcription inhibitor actinomycin-D; in the control (devoid of actinomycin-D), a classical apoptotic profile is observed with PGC movement, as already described [23], and in actinomycin-D-treated larvae PGC migration is blocked and PGC nuclei become TUNEL-positive, indicating

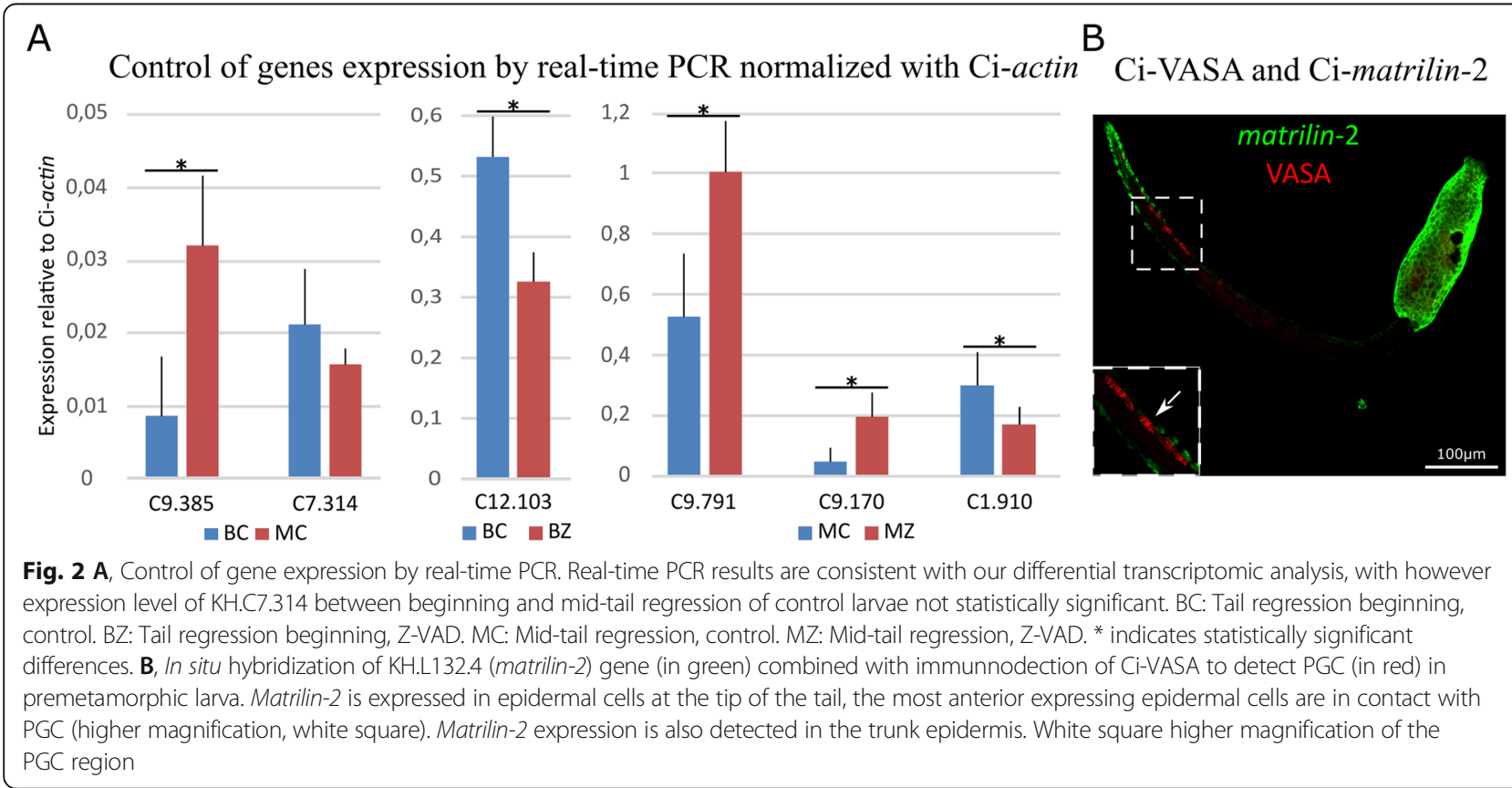


Table 1 Genes upregulated at mid-tail regression in comparison to the beginning

\begin{tabular}{|c|c|c|c|}
\hline $\begin{array}{l}\text { KyotoGrail KH gene } \\
\text { model }\end{array}$ & $\begin{array}{l}\text { Expression } \\
\text { ratio }\end{array}$ & Identity and/or GO function & $\begin{array}{l}\text { References in ascidians/ } \\
\text { reported functions in animals }\end{array}$ \\
\hline KH.C9.385 & 77,151 & histone-lysine N-methyltransferase SMYD3 & $x$ \\
\hline KH.C3.865 & 64,573 & orphan gene & $x$ \\
\hline KH.C6.306 & 33,673 & glutamate receptor ionotropic, kainate 2 (GRIK2) & $x$ \\
\hline KH.C11.563 & 31,576 & Breast cancer metastasis-suppressor 1 & $x$ \\
\hline KH.L104.1 & 19,902 & unnamed protein product & $x$ \\
\hline KH.C3.199 & 17,833 & $26 \mathrm{~S}$ proteasome regulatory subunit (RPT4B) & $x$ \\
\hline KH.C1.666 & 13,954 & uncharacterized LOC100178010 & $x$ \\
\hline KH.C8.321 & 12,169 & S-adenosyl-L-methionine-dependent methyltransferase & $x$ \\
\hline KH.C10.250 & 7367 & Fox-1, RNA-binding & $x$ \\
\hline KH.C2.196 & 5222 & Integrin alpha $\mathrm{N}$-terminal domain & migration \\
\hline KH.C3.423 & 4798 & At3g29763 & $x$ \\
\hline KH.S403.3 & 4672 & $\begin{array}{l}\text { Periplasmic binding protein-like II, UBX domain-containing protein } \\
1\end{array}$ & $x$ \\
\hline KH.S403.8 & 4672 & RSL1D1 & $x$ \\
\hline KH.C12.538 & 2968 & V-type proton ATPase subunit F-like (ATP6V1F) & $x$ \\
\hline KH.L133.11 & 2668 & protein 248-like; ubiquitine like & $x$ \\
\hline KH.C4.370 & 2541 & ADAMTS-like protein & $x$ \\
\hline KH.C1.489 & 2389 & serpin $\mathrm{H} 1$; serpin $\mathrm{A} 5$ & $x$ \\
\hline KH.C4.134 & 2290 & Spermadhesin; MAM and LDL-receptor class A & $x$ \\
\hline KH.C4.93 & 2270 & Zonadhesin; MAM and LDL-receptor class A & $x$ \\
\hline KH.C2.1060 & 2210 & uncharacterized protein LOC100177726 & $x$ \\
\hline KH.C1.22 & 2196 & ubiquitin-conjugating enzyme E2 D3-like (UBE2D3) & $x$ \\
\hline KH.C4.777 & 2134 & sushi, EGF and pentraxin domain-containing protein 1-like & $x$ \\
\hline KH.C1.72 & 2096 & zinc finger protein Ap-Zic & $x$ \\
\hline KH.C13.148 & 2016 & cochlin & $x$ \\
\hline KH.C13.178 & 2006 & uncharacterized protein LOC100185406 & $x$ \\
\hline
\end{tabular}

destruction as the apoptotic wave progresses (Fig. 3). This result, and our previous studies, argue that survival and migration of PGC depend on transcription that could be partially controlled by caspase activity from apoptotic cells (Fig. 3). The comparative transcriptomic analysis between control and Z-VAD-fmk treated larvae is fundamental to understand this apoptotic dependent migration.

\section{Discussion}

\section{Caspase activity modulates expression of genes} implicated in cell death/survival

Interestingly, the 2 genes most inhibited by caspase activity at the beginning of tail regression, girdin and mucin-5 $A C$, were both reported to promote survival in mammalian cells $[32,33]$. Among the other genes negatively impacted by caspase activity, KH.C1.1084, the thioredoxin homologue in mammals, is able to control the activation of the executioner caspase 3 , the initiator caspase 9, and the release of the cytochrome c, all characterising the intrinsic apoptosis [34-37]. In addition, KH.C3.45 (kinase $C$ alpha) homologue is known to promote survival and increases anti-apoptotic Bcl-2 efficiency in cultured cells [38]. Taken together, our database highlights that cells expressed a variety of genes regulating cell death/survival fate in a caspase dependent manner, suggesting that apoptotic cells actively participate in apoptosis propagation during tail regression.

\section{Caspase activity modulates expression of genes implicated in cell migration}

We identified numerous genes modulated by caspase activity, with a majority of them upregulated, previously observed in cell migration regulation. It is the case of KH.C1.216 (myosin light chain 3) and KH.C9.494 (myosin light chain kinase) for which homologues are key players in mesenchymal migration [32, 39] and KH.C13.153 (uromodulin-like) which provides guidance cues for neutrophile migration [40]. Furthermore, 
Table 2 Genes downregulated at mid-tail regression in comparison to the beginning

\begin{tabular}{|c|c|c|c|}
\hline $\begin{array}{l}\text { KyotoGrail KH gene } \\
\text { model }\end{array}$ & $\begin{array}{l}\text { Expression } \\
\text { ratio }\end{array}$ & Identity and/or GO function & $\begin{array}{l}\text { References in ascidians/reported } \\
\text { functions in animals }\end{array}$ \\
\hline KH.C14.261 & 0,023 & putative lysozyme-like protein; PE-PGRS family protein & $x$ \\
\hline KH.L37.67 & 0,025 & TGM1, Transglutaminase & $x$ \\
\hline KH.C7.501 & 0,026 & ferritin & $x$ \\
\hline KH.C1.459 & 0,026 & Sorting nexin-18 & $x$ \\
\hline KH.C4.177 & 0,028 & Glucocorticoid receptor-like, Pinch protein & $x$ \\
\hline KH.C7.314 & 0,050 & mediator of RNA polymerase 2 transcription subunit 30 (med30) & $\begin{array}{l}\text { Chambon et al. } 2007 \\
\text { (ci0100134193) } \\
\text { apoptosis }\end{array}$ \\
\hline KH.C14.281 & 0,050 & glycerol-3-phosphate (1)-acyltransferase & $x$ \\
\hline KH.L142.4 & 0,056 & universal stress protein YxiE & $x$ \\
\hline KH.C1.263 & 0,061 & ribosomal protein $L 4$ & $x$ \\
\hline KH.C10.335 & 0,061 & calmodulin like protein & migration \\
\hline KH.C11.384 & 0,092 & uncharacterized protein LOC100186758 & $x$ \\
\hline KH.L112.30 & 0,103 & transmembrane matrix receptor MUP-4-like & $x$ \\
\hline KH.C1.1024 & 0,129 & glutamate-rich WD repeat-containing protein 1 & $x$ \\
\hline KH.C4.94 & 0,129 & lipopolysaccharide-induced tumor necrosis factor-alpha factor & $x$ \\
\hline KH.L92.1 & 0,144 & protein DDB_G0283697 & $x$ \\
\hline KH.C2.124 & 0,155 & Glycerol-3-phosphate (1)-acyltransferase & $x$ \\
\hline KH.L108.23 & 0,167 & protein DD3-3 & $x$ \\
\hline KH.C11.93 & 0,174 & $\mathrm{~N}$-acetyltransferase 6 & $x$ \\
\hline KH.C10.133 & 0,194 & holine-phosphate cytidylyltransferase A-like & $x$ \\
\hline KH.C3.231 & 0,216 & uncharacterized protein LOC100184171 & $x$ \\
\hline KH.L59.3 & 0,227 & uncharacterized protein LOC100175851 & $x$ \\
\hline KH.C4.450 & 0,235 & $\begin{array}{l}\text { sushi, von Willebrand factor type A, EGF and pentraxin domain- } \\
\text { containing protein } 1\end{array}$ & $x$ \\
\hline KH.C11.274 & 0,243 & P-selectin-like & $\begin{array}{l}\text { Chambon et al. } 2007 \\
\text { (ci0100139289) } \\
\text { apoptosis }\end{array}$ \\
\hline KH.C4.73 & 0,268 & uncharacterized protein LOC100175287 & $x$ \\
\hline KH.C14.356 & 0,275 & putative lysozyme-like protein & $x$ \\
\hline KH.C11.287 & 0,278 & unc-93 homolog A-like & $x$ \\
\hline KH.C14.337 & 0,313 & lysozyme-like protein; PE-PGRS family protein PE_PGRS30 & $x$ \\
\hline KH.C14.549 & 0,335 & lysozyme-like protein; PE-PGRS family protein PE_PGRS30 & $x$ \\
\hline KH.L108.30 & 0,344 & uromodulin-like 1 precursor & migration \\
\hline KH.C12.655 & 0,390 & uncharacterized protein LOC113474772 & $x$ \\
\hline KH.L132.16 & 0,428 & fibrillin-3; MATN2 & migration \\
\hline KH.L132.4 & 0,428 & matrilin-2; MEGF6 & $\begin{array}{l}\text { Chambon et al. } 2007 \\
\text { (ci0100138016) } \\
\text { migation }\end{array}$ \\
\hline KH.C2.613 & 0,443 & zinc transporter 9-like & $x$ \\
\hline KH.C11.454 & 0,446 & uncharacterized protein LOC100184022 & $x$ \\
\hline KH.C8.121 & 0,463 & SCO-spondin & $x$ \\
\hline KH.C4.402 & 0,470 & galanin receptor type 3 & $x$ \\
\hline
\end{tabular}


Table 3 Genes upregulated by the Z-VAD-fmk at the tail regression beginning

\begin{tabular}{llll}
\hline KyotoGrail KH gene model & Expression ratio & Identity and/or GO function & $\begin{array}{l}\text { References in ascidians/reported } \\
\text { functions in animals }\end{array}$ \\
\hline KH.C11.506 & 9850 & girdin & apoptosis \\
KH.S1380.1 & 7405 & mucin-5 AC & apoptosis \\
KH.C8.46 & 4453 & vesicle-associated membrane protein 4-like & $\times$ \\
KH.C1.451 & 4028 & orphan gene & $\times$ \\
KH.C14.511 & 3917 & myotubularin-related protein 2-like & $\times$ \\
KH.L41.62 & 3503 & reticulocalbin-2-like & $\times$ \\
KH.L152.1 & 3305 & proline-rich protein PRCC & $\times$ \\
KH.C11.93 & 2521 & gamma-glutamylcyclotransferase 2; & $\times$ \\
KH.C11.218 & N-acetyltransferase 6 & $\times$ \\
KH.C1.1084 & 2463 & cytospin-A isoform X1 & apoptosis \\
KH.L106.13 & 2290 & thioredoxin-2-like & $\times$ \\
KH.C12.373 & 2121 & DENN domain-containing protein 5B-like & $\times$ \\
\hline
\end{tabular}

integrin subunits and components of the Extra Cellular Matrix, crucial for mesenchymal migration, are well represented in our transcriptomic approach. In addition, KH.C1.10 (lasp1) mammalian homolog is necessary for migration of NIH 3 T3 cells [41, 42].

Furthermore, KH.C12.516 (ceramidase) could be involved in tissue migration regulation, as it has been described as participating in the sphingolipid pathways. Interestingly, sphingosine 1-phosphate signalling leads to tissue migration [43], particularly in germline cells (due to to a sphingosine 1-phosphate receptor) in the tunicate Botryllus [44], making this pathway a strong candidate for PGC migration in Ciona. Given that these genes and PGC migration are both controlled by caspases [23], PGC migration can be regulated by apoptotic cells.

\section{Ascidians as crucial biological models to studies novel apoptotic function}

This study, coupled with our previous work suggested that apoptosis regulates the migration of primordial germ cells [23], confirm Ciona as a perfect biological model to understand apoptotic-induced migration. In addition, a regulation of cell proliferation by apoptosis was reported in this species [45]. Ascidians are well known to have an impressive regenerative capacity for a chordate, in particular in the context of the reconstruction of the distal body parts after amputation, thanks to stem cell requisition from the branchial sac [46-48]. Apoptosis was reported to occur as a transient event at the site of injury, and precedes the regeneration of the neural complex, the oral siphon, or the atrial siphon [49]. In the case of siphon amputation, it has been shown by caspases inhibition experiment that an apoptotic-dependant Wnt signalling allows the cell proliferation, leading to the successful regeneration [45]. In addition, apoptosis appears crucial to maintain the growth of branchial sac and its inhibition lead to a hazardous organization of this tissue, suggesting a fundamental function in homeostasis maintaining. Importantly, stem cells requisition and migration from the branchial sac toward the wounding site seem also dependant on caspases, making it an other potential

Table 4 Genes downregulated by the Z-VAD-fmk at the tail regression beginning

\begin{tabular}{llll}
\hline KyotoGrail KH gene model & Expression ratio & Identity and/or GO function & References in ascidians/reported functions in animals \\
\hline KH.L92.1 & 0,473 & protein DDB_G0283697 & $\times$ \\
KH.C6.197 & 0,449 & META2 protein precursor & Nakayama et al., 2001-2002; Chambon et al., 2007 \\
KH.C1.216 & 0,369 & myosin light chain 3, skeletal muscle & Nakayama et al., 2002 \\
KH.L24.20 & 0,366 & collagen alpha-6(VI) chain-like & migration \\
KH.L154.8 & 0,309 & unnamed protein product & $x$ \\
KH.C13.153 & 0,308 & uromodulin-like & migration \\
KH.C3.237 & 0,229 & 60S ribosomal protein L7a & $x$ \\
KH.C12.103 & 0,098 & nuclear lamin-L (II)-like & $x$ \\
KH.C1.66 & 0,000 & orphan gene & $x$ \\
\hline
\end{tabular}


Table 5 Genes upregulated by the Z-VAD-fmk at mid-tail regression

\begin{tabular}{|c|c|c|c|}
\hline KyotoGrail KH gene model & Expression ratio & Identity and/or GO function & $\begin{array}{l}\text { References in ascidians/reported } \\
\text { functions in animals }\end{array}$ \\
\hline KH.C12.516 & 11,357 & neutral ceramidase-like & $\begin{array}{l}\text { Kassmer et al. (2015) } \\
\text { migration }\end{array}$ \\
\hline KH.C9.170 & 10,571 & protein CNPPD1 & $x$ \\
\hline KH.C2.541 & 7634 & cell cycle control protein 50A & $x$ \\
\hline KH.C3.623 & 7551 & kinesin-like protein 2 & $x$ \\
\hline KH.C4.189 & 6713 & ribosomal protein CEP52 & $x$ \\
\hline KH.L124.15 & 5285 & vesicular integral-membrane protein VIP36 & $x$ \\
\hline KH.S522.7 & 5242 & TPA: zinc finger protein & $x$ \\
\hline KH.C14.231 & 4625 & 605 ribosomal protein L12 & $x$ \\
\hline KH.S605.3 & 4398 & gamma-crystallin S & $x$ \\
\hline KH.C9.791 & 4198 & integrin alpha-2-like & migration \\
\hline KH.C4.73 & 4127 & uncharacterized protein LOC100175287 & $x$ \\
\hline KH.L5.23 & 4122 & uncharacterized protein LOC100179749 & $x$ \\
\hline KH.C1.568 & 3255 & uncharacterized protein LOC100176279 & $x$ \\
\hline KH.S390.2 & 3227 & RNA-binding motif, single-stranded-interacting protein 1 & $x$ \\
\hline KH.C9.660 & 3187 & supervillin-like & migration \\
\hline KH.L106.13 & 3179 & DENN domain-containing protein 5B-like & $x$ \\
\hline KH.S534.8 & 3075 & coiled-coil domain-containing protein 178-like & $x$ \\
\hline KH.L108.23 & 2846 & protein DD3-3 & $x$ \\
\hline KH.C7.614 & 2824 & SLIT and NTRK-like protein 3 & $x$ \\
\hline KH.C2.448 & 2822 & plasminogen & $x$ \\
\hline KH.C7.297 & 2732 & solute carrier family 22 member 21 & $x$ \\
\hline KH.L37.43 & 2586 & L-threonine ammonia-lyase & $x$ \\
\hline KH.C11.274 & 2571 & P-selectin-like & $\begin{array}{l}\text { Chambon et al., } 2007 \\
\text { (ci0100139289) } \\
\text { apoptosis }\end{array}$ \\
\hline KH.C11.218 & 2518 & cytospin-A & $x$ \\
\hline KH.L59.3 & 2488 & uncharacterized protein LOC100175851 & $x$ \\
\hline KH.C10.71 & 2418 & 3-phosphoinositide-dependent protein kinase 1 & $x$ \\
\hline KH.C9.715 & 2397 & neurobeachin-like protein 1 & $x$ \\
\hline KH.C3.562 & 2392 & unconventional myosin- $X$ & $x$ \\
\hline KH.C4.94 & 2374 & lipopolysaccharide-induced tumor necrosis factor-alpha factor & $x$ \\
\hline KH.S534.2 & 2333 & RB1-inducible coiled-coil protein 1 & $x$ \\
\hline KH.C9.496 & 2327 & uncharacterized protein LOC100183253 & $x$ \\
\hline KH.C1.10 & 2314 & LIM and SH3 protein & Terasaki et al., 2008 \\
\hline KH.C11.93 & 2252 & $\mathrm{~N}$-acetyltransferase 6 & $x$ \\
\hline KH.L112.30 & 2179 & transmembrane matrix receptor MUP-4-like & $x$ \\
\hline KH.C11.567 & 2162 & serine palmitoyltransferase 2 & $x$ \\
\hline KH.L23.11 & 2094 & uncharacterized protein LOC100178692 & $x$ \\
\hline KH.C11.637 & 2056 & putative glutathione-specific gamma-glutamylcyclotransferase 2 & $x$ \\
\hline KH.C7.260 & 2031 & tropomyosin-like protein & $\begin{array}{l}\text { Nakayama et al., } 2002 \\
\text { migration }\end{array}$ \\
\hline
\end{tabular}


Table 6 Genes down regulated by the Z-VAD-fmk at mid-tail regression

\begin{tabular}{llll}
\hline KyotoGrail KH gene model & Expression ratio & Identity and/or GO function & $\begin{array}{l}\text { References in ascidians/reported } \\
\text { functions in animals }\end{array}$ \\
\hline KH.C11.688 & 0,385 & thioredoxin-related transmembrane protein 1-like & $\times$ \\
KH.C9.494 & 0,319 & myosin light chain kinase, smooth muscle & $\begin{array}{l}\text { Nakayama et al., 2002 } \\
\text { migration }\end{array}$ \\
KH.C3.865 & 0,270 & orphan gene & $\times$ \\
KH.C7.361 & 0,237 & regulator of chromosome condensation 1 (rcc1) & $\times$ \\
KH.C3.45 & 0,217 & protein kinase C alpha type & Apoptosis \\
KH.C1.910 & 0,109 & low-density lipoprotein receptor-related protein 2 & $\times$ \\
\hline
\end{tabular}

apoptotic-dependant migration [45]. Taken together, all of these studies make Ciona one of the rare biological models where several cell fates and behaviours, controlled by apoptotic cells in a caspases dependent manner, has been put in evidence or suggested in adults as well as in larvae.

In the colonial ascidian Botryllus schlosseri, apoptosis is known to play on budlets elimination [50-52]. In this species, blastogenetic cycle (asexual reproduction of adults) give rise to a bud, itself given next four budlets (reviewed in $[53,54]$ ). Usually, two of them growth despite the two other undergo apoptosis and are reabsorbed. In addition to this function in the blastogenetic cycle, apoptosis was also reported in tunic, epidermis, branchial leaflet, vessel epithelium, circulatory system or gonads in adults. With so many tissues presenting apoptosis in physiological condition, it seems clear that apoptosis should have crucial functions in Botryllus and likely could participate to regulation of other cell fates and behaviours as it was reported in Ciona. All of these tissues are as many opportunities to deepen or understanding of apoptosis functions in a same species.

\section{Conclusions}

Here, we offer a potential roadmap in order to design future functional studies on Ciona and other animals, including mammals, where apoptosis takes place together with other cell fates and behaviours. Identification of molecular actors needing cleavage for their activation, cell receptors receiving signals from apoptotic cells, or

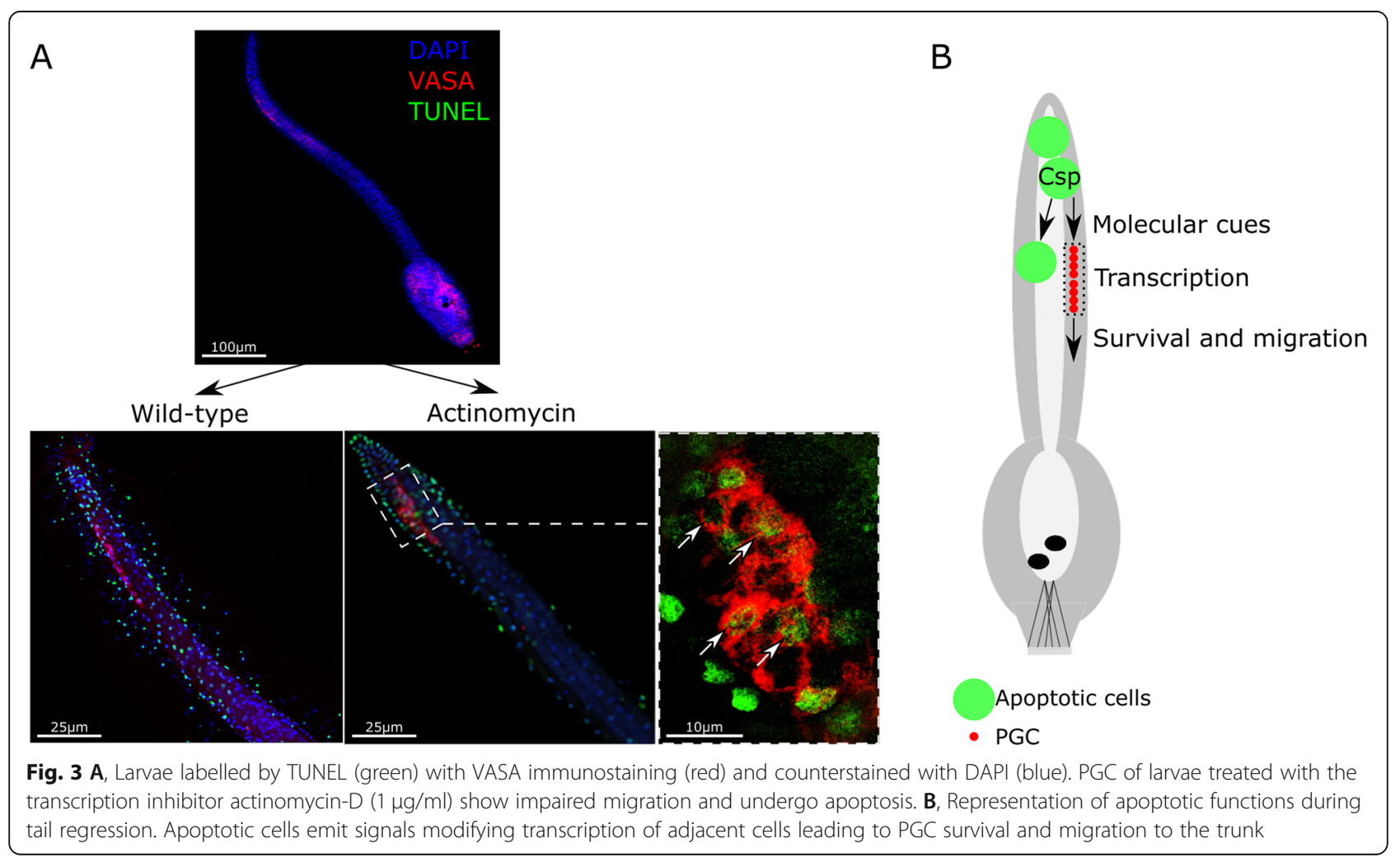


transcription factors could be promising for further research.

The last decade has brought evidence that the cleavage capacity of caspases is a prerequisite to activate molecular actors promoting migration or differentiation in a non-apoptotic context [55-59]. Consequently, Z-VADfmk blocks all processes led by caspases, making it crucial to distinguish the level of implication of apoptotic and non-dying cells for future research.

Finally, our study provides an additional and novel chapter in the research of apoptotic functions beyond their role as a simple cell elimination mechanism, opening opportunities in the field of medical science [60].

\section{Methods}

\section{Sample collection}

Adult Ciona intestinalis were collected in the field in Brittany (France) by the Centre National Marine Biological Resources, EMBRC-France, Roscoff (Station Biologique de Roscoff, Sorbonne Université, Brittany, France). Individuals were maintained in $35 \%$ salinity artificial seawater (ASW) at $18{ }^{\circ} \mathrm{C}$ in the UMR7138 Evolution Paris Seine laboratory (Sorbonne University, Paris, France). Oocytes and sperm were obtained by dissection and cross-fertilizations were performed in plastic Petri dishes. Embryos were cultured at $18{ }^{\circ} \mathrm{C}$ in $0.2 \mu \mathrm{m}$ filtered ASW with $0.1 \mathrm{M}$ Hepes (\#H4034, Sigma-Aldrich; Merck KGaA). Embryos of each fertilisation were divided into two subsets before the first cell division to obtain one control and one treatment condition. Six fertilisations were performed, divided into twelve petri dishes (6 control with their respective 6 treatment conditions). After the treatment, larvae were collected at two time points (see below), and compacted by manual centrifugation before RNA extraction.

\section{Pharmacological treatments and TUNEL labelling}

The pan-caspase inhibitor Z-VAD-Fmk (\#V116, SigmaAldrich; Merck KGaA) was stored in DMSO (\#D8418, Sigma-Aldrich; Merck KGaA) at $-20^{\circ} \mathrm{C}$ and used at final concentration of $10 \mu \mathrm{M}$. After the settlement of more than $50 \%$ of larvae on the dish, and when some of them stopped moving (indicating that metamorphosis will begin soon), supernatant was discarded and replaced with filtered ASW containing DMSO as control, or ZVAD-Fmk diluted in DSMO as treatment. Z-VAD-Fmk was renewed every two hours. The experiment was divided into two time points (with three biological replicates for each one - itself divided between control and treated larva) following control tail regression stages: first when the tail regression just began in the control (beginning), and the second at mid-progression (mid-tail regression) given three controls with three Z-VAD-Fmk equivalents for each point.
In a separate experiment, $1 \mu \mathrm{g} / \mathrm{ml}$ of actinomycin-D (\#A1410, Sigma-Aldrich; Merck KGaA) was added to swimming larvae. After settlement and tail regression initiation, paraformaldehyde fixation, TUNEL labelling and Vasa immunostaining were performed as previously described [23].

\section{RNA preparation and sequencing}

RNA was extracted using the RNAqueous ${ }^{\text {TwN}}$-Micro Total RNA Isolation Kit (\#AM1931 - ThermoFisher Scientific) according to the manufacturer's protocol. DNAse treatment was performed using the TURBO DNA-free ${ }^{\mathrm{Tw}} \mathrm{Kit}$ (\#AM1907 - ThermoFisher Scientific). RNA was purified and concentrated using the RNeasy MinElute Cleanup Kit (\#74204 - Qiagen) according to the manufacturer's protocol. RNA quantity was measured using a NanoDrop and quality was assessed with the Experion RNA HighSens (\#700-7155 - BioRad) from $1 \mu \mathrm{L}(0.1 \mu \mathrm{L}$ of RNA completed with $0.9 \mu \mathrm{L}$ of Milli-Q water) following standard instructions. Transcriptomes were sequenced on Illumina Hi-Seq 2000 (150 bp reads) at the Sistemas Genomicos plate-form of the Ascires Biomedical Group (Spain).

\section{De novo transcriptome assembly and differential expression}

Raw reads of the twelve Ciona intestinalis samples were checked with FastQC and merged to assemble a de novo transcriptome with Oases [61] and Trinity [62]. Best assemblies from each one (best N50) were merged with Cap3 to obtain the de novo transcriptome. De novo transcriptome contains 85,506 contigs $(\mathrm{N} 50=1314$, minimum contig length $=102$, maximum contig length $=$ 13,998). Then, raw reads of each sample were mapped against the de novo transcriptome with Bowtie2 [63] with standard parameters. Low quality mapping reads (MQ > 20) were removed using Samtools [64] and Picard Tools (http://broadinstitute.github.io/picard). Expression quantification was performed using HTSeq [65] and differential expression evaluated with the DESeq2 package from $\mathrm{R}$. We kept the genes with an expression ratio (control $1+$ control $2+$ control 3) / (treatment $1+$ treatment $2+$ treatment 3 ) - above 2 (upregulated) and lower than 0.5 (downregulated). Then, Gene Ontology (GO) enrichment was performed with Blast2GO 5.2 and sequences were blasted on the Ciona genome to identify their KyotoGrail KH gene model.

\section{Real-time PCR}

We synthetised the cDNA from RNA coming from same sample which was sending for sequencing using the SuperScript $^{\text {Tm }}$ II Reverse Transcriptase (18,064,014 ThermoFisher Scientific) according to the manufacturer protocol. Real-time PCR was performed with the SYBR 
Green Supermix (Biorad) on a Biorad's thermal cycler with the following profile: $95^{\circ} \mathrm{C}$ for $10 \mathrm{~min}$; 40 cycles of amplification with successively $95^{\circ} \mathrm{C}$ for $15 \mathrm{~s}, 60^{\circ} \mathrm{C}$ for $10 \mathrm{~s}$, and $72^{\circ} \mathrm{C}$ for $20 \mathrm{~s}$; one cycle for melting curve analysis with an acquisition every $0.5^{\circ} \mathrm{C}$ from $65^{\circ} \mathrm{C}$ to $95^{\circ} \mathrm{C}$ to verify the presence of a single product. Each assay included four successive dilutions as standard to determine the reaction efficiencies and $\mathrm{Ct}$ values. Reactions were done in triplicate. All PCR amplicon have a length from 140 to $160 \mathrm{bp}$. Normalized was made using the reference gene Ci-actin (forward 5' ATGTGCAAGG CCGGTTT 3'; reverse 5' GACACGGAGTTCGTTGT $\left.3^{\prime}\right)$, already successfully used [66]. Genes of interest and their primer pair are: KH.C9.385 with forward $5^{\prime}$ ACTT CTGAAAAGAGCGGACG $3^{\prime}$ and reverse 5' CATTGCAACAGACCATCTTGC 3', KH.C7.314 with forward 5' AGCCAACTACCGAATGGGA $3^{\prime}$ and reverse 5' GTTCCACGTCTCCAACTCTC 3', KH.C12.103 with forward 5' TGTCTGAGATACGAAAGCGT 3' and reverse 5' CATTTGCTCAAGATCGGCG 3', KH.C9.791 with forward 5' GGATCTAAGCACTGTTCTGGAC 3' and reverse 5' CAAGGGCGTTGGTGTTCAGT 3', KH.C9.170 with forward 5' AATCCCCGCCCTTGAA GAAA $3^{\prime}$ and reverse 5' GGGGTGGATATGAATAAC ATGG 3', and KH.C1.910 with forward 5' ACATGAAG ATTTTGGTACCGAC $3^{\prime}$ and reverse $5^{\prime}$ CAAAAC TTGGCCAAAAAGTTGG 3'. Differences was evaluated by Wilcoxon Mann-Whitney tests using $\mathrm{R}$ i386 4.0.3 software, and considered statistically significant for $p$-value $<0.05$.

\section{In situ hybridization combined with vasa immunnodetection}

Larvae were fixed $2 \mathrm{~h}$ at $4{ }^{\circ} \mathrm{C}$ in MEM-PFA (4\% paraformaldehyde, $0.1 \mathrm{M}$ MOPS $\mathrm{pH} 7.4,0.1 \mathrm{M} \mathrm{NaCl}, 1 \mathrm{mM}$ EGTA, and $2 \mathrm{mM} \mathrm{MgSO} 4,0.05 \%$ Tween-20). After fixation larvae were washed three times and dehydrated through a graded series of ethanol/PBS baths and stocked in $100 \%$ ethanol at $-20^{\circ} \mathrm{C}$. Rehydratation was made by successive washes of ethanol/PBS solution to a full PBS final solution. Hybridization was made according to a previous protocol [67] except that methanol was replaced by ethanol. After hybridization, immunnodetection of VASA was conducted as we previously described [23].

\section{Supplementary Information}

The online version contains supplementary material available at https://doi. org/10.1186/s12860-021-00388-0.

Additional file 1: Supplementary Fig. 1. Experimental design. Six independent fertilisations were performed, and each of them was divided into two batches, in twelve petri dishes. After settlement, supernatant was discarded and replaced with filtered ASW containing DMSO (control) or Z-VAD-Fmk diluted in DSMO (treatment). RNA sampling was done at two time points according to the control: immediately after observation of tail regression beginning, and at mid-tail regression.

\section{Acknowledgements}

The authors strongly acknowledge Muriel Jager (Sorbonne Université, Paris, France), Thierry Jaffredo (Sorbonne Université, Paris, France), and the IBPS Proteomic facility (Sorbonne Université, Paris, France) for technical support. We thank Uri Frank (National University of Ireland Galway, Galway, Ireland) and Helen Horkan (National University of Ireland Galway, Galway, Ireland) for useful comments.

\section{Authors' contributions}

JP managed the project and made in situ hybridization. GK performed ZVAD-fmk experiments, RNA extractions, real-time PCR, analysis, created figures and wrote the manuscript. AK performed actinomycin and TUNEL experiments. All authors contributed to comments on the manuscript. The authors read and approved the final manuscript.

\section{Funding}

This work was supported by the Fondation ARC pour la recherche sur le cancer grant n $n^{\circ}$ PJA 20141201892 to JP. The work of GK was supported by a Ph.D. fellowship from the French Ministry of Education, Research and Innovation.

\section{Availability of data and materials}

Any request can be addressed to the corresponding author. Raw data are available under BioProject PRJNA725676.

\section{Declarations}

\section{Ethics approval and consent to participate}

According to the French legislation (Décret n²013-118 du 1er février 2013 relatif à la protection des animaux utilisés à des fins scientifiques), experiments on Ciona intestinalis do not require an approval from Animal Ethics Commission because its not a "live vertebrate animals" and not a "live cephalopods".

\section{Consent for publication}

Not applicable.

\section{Competing interests}

The authors declare that they have no competing interests.

\section{Author details}

${ }^{1}$ Institut de Systématique, Evolution, Biodiversité (ISYEB), UMR 7205, Sorbonne Université, Muséum National d'histoire Naturelle, CNRS, EPHE, 7 Quai St-Bernard, F-75252 Paris Cedex 05, France. ${ }^{2}$ Center for Chromosome Biology, School of Natural Sciences, National University of Ireland Galway, Galway, Ireland. ${ }^{3}$ INSERM UMRS_938, Centre de recherche Saint-Antoine (CRSA), Sorbonne Université, Paris, France. ${ }^{4}$ Centre de Recherche de Biologie Cellulaire de Montpellier (CRBM), Montpellier Univ., CNRS, 34000 Montpellier, France.

Received: 22 April 2021 Accepted: 12 August 2021

Published online: 06 October 2021

References

1. Kerr JF, Wyllie AH, Currie AR. Apoptosis: a basic biological phenomenon with wide-ranging implications in tissue kinetics. Br J Cancer. 1972;26(4): 239-57. https://doi.org/10.1038/bjc.1972.33.

2. Hengartner MO. The biochemistry of apoptosis. Nature. 2000;407(6805):7706. https://doi.org/10.1038/35037710.

3. Galluzzi L, Vitale I, Aaronson SA, Abrams JM, Adam D, Agostinis P, et al. Molecular mechanisms of cell death: recommendations of the nomenclature committee on cell death 2018. Cell Death Differ. 2018;25(3): 486-541. https://doi.org/10.1038/s41418-017-0012-4.

4. Lasi M, David CN, Böttger A. Apoptosis in pre-Bilaterians: Hydra as a model. Apoptosis. 2010;15(3):269-78. https://doi.org/10.1007/s10495-009-0442-7. 
5. Accordi F, Chimenti C. Programmed cell death in the pancreas of Bufo bufo during metamorphosis. J Anat. 2001;199(Pt 4):419-27. https://doi.org/10.104 6/j.1469-7580.2001.19940419.x.

6. Kiss T. Apoptosis and its functional significance in molluscs. Apoptosis. 2010; 15(3):313-21. https://doi.org/10.1007/s10495-009-0446-3.

7. Jiang C, Baehrecke EH, Thummel CS. Steroid regulated programmed cell death during Drosophila metamorphosis. Development. 1997;124(22):467383. https://doi.org/10.1242/dev.124.22.4673.

8. Jacobson MD, Weil M, Raff MC. Programmed cell death in animal development. Cell. 1997;88(3):347-54. https://doi.org/10.1016/S0092-8674 (00)81873-5

9. Wood W, Turmaine M, Weber R, Camp V, Maki RA, McKercher SR, et al. Mesenchymal cells engulf and clear apoptotic footplate cells in macrophageless PU.1 null mouse embryos. Development. 2000;127(24): 5245-52. https://doi.org/10.1242/dev.127.24.5245.

10. Nishikawa A, Hayashi H. Spatial, temporal and hormonal regulation of programmed muscle cell death during metamorphosis of the frog Xenopus laevis. Differentiation. 1995;59(4):207-14. https://doi.org/10.1046/j.1432-043 6.1995.5940207.x.

11. Furuta I, Porkka-Heiskanen T, Scarbrough K, Tapanainen J, Turek FW, Hsueh AJ. Photoperiod regulates testis cell apoptosis in Djungarian hamsters. Biol Reprod. 1994;51(6):1315-21. https://doi.org/10.1095/biolreprod51.6.1315.

12. Fogarty CE, Bergmann A. The sound of silence: signaling by apoptotic cells. Curr Top Dev Biol. 2015;114:241-65. https://doi.org/10.1016/bs.ctdb.2015.07. 013.

13. Fuchs $Y$, Steller $H$. Live to die another way: modes of programmed cell death and the signals emanating from dying cells. Nat Rev Mol Cell Biol. 2015;16(6):329-44. https://doi.org/10.1038/nrm3999.

14. Chera S, Ghila L, Dobretz K, Wenger Y, Bauer C, Buzgariu W, et al. Apoptotic cells provide an unexpected source of Wnt3 signaling to drive hydra head regeneration. Dev Cell. 2009;17(2):279-89. https://doi.org/10.1016/j.devcel.2 009.07.014.

15. Li F, Huang Q, Chen J, Peng Y, Roop DR, Bedford JS, et al. Apoptotic cells activate the "phoenix rising" pathway to promote wound healing and tissue regeneration. Sci Signal. 2010;3:ra13.

16. Wittig K, Kasper J, Seipp S, Leitz T. Evidence for an instructive role of apoptosis during the metamorphosis of Hydractinia echinata (Hydrozoa). Zoology (Jena). 2011;114(1):11-22. https://doi.org/10.1016/j.zool.2010.09.004.

17. Bilak A, Uyetake L, Su TT. Dying cells protect survivors from radiationinduced cell death in Drosophila. PLoS Genet. 2014;10(3):e1004220. https:// doi.org/10.1371/journal.pgen.1004220.

18. Lauber K, Bohn E, Kröber SM, Xiao Y, Blumenthal SG, Lindemann RK, et al. Apoptotic cells induce migration of phagocytes via caspase-3-mediated release of a lipid attraction signal. Cell. 2003;113(6):717-30. https://doi.org/1 0.1016/S0092-8674(03)00422-7.

19. Gude DR, Alvarez SE, Paugh SW, Mitra P, Yu J, Griffiths R, et al. Apoptosis induces expression of sphingosine kinase 1 to release sphingosine-1phosphate as a "come-and-get-me" signal. FASEB J. 2008;22(8):2629-38. https://doi.org/10.1096/fj.08-107169.

20. Tseng A-S, Adams DS, Qiu D, Koustubhan P, Levin M. Apoptosis is required during early stages of tail regeneration in Xenopus laevis. Dev Biol. 2007; 301(1):62-9. https://doi.org/10.1016/j.ydbio.2006.10.048.

21. Chambon J-P, Soule J, Pomies P, Fort P, Sahuquet A, Alexandre D, et al. Tail regression in Ciona intestinalis (Prochordate) involves a caspase-dependent apoptosis event associated with ERK activation. Development. 2002;129(13): 3105-14. https://doi.org/10.1242/dev.129.13.3105.

22. Jeffery WR. Programmed cell death in the ascidian embryo: modulation by FoxA5 and Manx and roles in the evolution of larval development. Mech Dev. 2002;118(1-2):111-24. https://doi.org/10.1016/S0925-4773(02)00236-8.

23. Krasovec G, Robine K, Quéinnec E, Karaiskou A, Chambon JP. Ci-hox12 tail gradient precedes and participates in the control of the apoptotic-dependent tail regression during Ciona larva metamorphosis. Dev Biol. 2019;448(2):237-46. https://doi.org/10.1016/j. ydbio.2018.12.010.

24. Shirae-Kurabayashi M, Nishikata T, Takamura K, Tanaka KJ, Nakamoto C, Nakamura A. Dynamic redistribution of vasa homolog and exclusion of somatic cell determinants during germ cell specification in Ciona intestinalis. Development. 2006;133(14):2683-93. https:/doi.org/10.1242/dev.02446.

25. Delsuc F, Brinkmann H, Chourrout D, Philippe $H$. Tunicates and not cephalochordates are the closest living relatives of vertebrates. Nature. 2006 439(7079):965-8. https://doi.org/10.1038/nature04336.
26. Kawai N, Ogura Y, Ikuta T, Saiga H, Hamada M, Sakuma T, et al. Hox10regulated endodermal cell migration is essential for development of the ascidian intestine. Dev Biol. 2015;403(1):43-56. https://doi.org/10.1016/j. ydbio.2015.03.018

27. Nakayama A, Satou Y, Satoh N. Isolation and characterization of genes that are expressed during Ciona intestinalis metamorphosis. Dev Genes Evol. 2001;211(4):184-9. https://doi.org/10.1007/s004270100133.

28. Nakayama A, Satou Y, Satoh N. Further characterization of genes expressed during Ciona intestinalis metamorphosis. Differentiation. 2002;70(8):429-37. https://doi.org/10.1046/j.1432-0436.2002.700805.x.

29. Chambon J-P, Nakayama A, Takamura K, McDougall A, Satoh N. ERK- and JNK-signalling regulate gene networks that stimulate metamorphosis and apoptosis in tail tissues of ascidian tadpoles. Development. 2007;134(6): 1203-19. https://doi.org/10.1242/dev.002220.

30. Terasaki AG, Hiruta J, Suzuki J, Sakamoto S, Nishioka T, Suzuki H, et al. A lasp family protein of Ciona intestinalis. Biochim Biophys Acta. 1779;2008(1):51-9. https://doi.org/10.1016/j.bbagrm.2007.08.001.

31. Kusakabe T, Yoshida R, Kawakami I, Kusakabe R, Mochizuki Y, Yamada L, et al. Gene expression profiles in tadpole larvae of Ciona intestinalis. Dev Biol. 2002;242(2):188-203. https://doi.org/10.1006/dbio.2002.0538.

32. Wang $S$, Lei $Y, C$ Cai $Z$, Ye $X$, Li L, Luo $X$, et al. Girdin regulates the proliferation and apoptosis of pancreatic cancer cells via the PI3K/Akt signalling pathway. Oncol Rep. 2018;40(2):599-608. https://doi.org/10.3 892/or.2018.6469

33. Hoshi H, Sawada T, Uchida M, lijima H, Kimura K, Hirakawa K, et al. MUC5AC protects pancreatic cancer cells from TRAlL-induced death pathways. Int J Oncol. 2013:42(3):887-93. https://doi.org/10.3892/ijo.2013.1760.

34. Nonn L, Williams RR, Erickson RP, Powis G. The absence of mitochondrial thioredoxin 2 causes massive apoptosis, exencephaly, and early embryonic lethality in homozygous mice. Mol Cell Biol. 2003;23(3):916-22. https://doi. org/10.1128/MCB.23.3.916-922.2003.

35. Tanaka T, Hosoi F, Yamaguchi-Iwai Y, Nakamura H, Masutani $H$, Ueda S, et al Thioredoxin-2 (TRX-2) is an essential gene regulating mitochondriadependent apoptosis. EMBO J. 2002;21(7):1695-703. https://doi.org/10.1093/ emboj/21.7.1695.

36. Baker A, Santos BD, Powis G. Redox control of caspase-3 activity by thioredoxin and other reduced proteins. Biochem Biophys Res Commun. 2000;268(1):78-81. https://doi.org/10.1006/bbrc.1999.1908.

37. Mitchell DA, Marletta MA. Thioredoxin catalyzes the S-nitrosation of the caspase-3 active site cysteine. Nat Chem Biol. 2005;1(3):154-8. https://doi. org/10.1038/nchembio720.

38. Reyland ME. Protein kinase C isoforms: Multi-functional regulators of cell life and death. Front Biosci (Landmark Ed). 2009;14:2386-99.

39. Wang $X$, Ye $X$, Ji J, Wang J, Xu B, Zhang Q, et al. MicroRNA-155 targets myosin light chain kinase to inhibit the migration of human bone marrowderived mesenchymal stem cells. Int J Mol Med. 2018;42(3):1585-92. https:// doi.org/10.3892/ijmm.2018.3718.

40. Schmid M, Prajczer S, Gruber LN, Bertocchi C, Gandini R, Pfaller W, et al. Uromodulin facilitates neutrophil migration across renal epithelial monolayers. Cell Physiol Biochem. 2010;26(3):311-8. https://doi.org/10.1159/ 000320554.

41. Grunewald TGP, Kammerer U, Schulze E, Schindler D, Honig A, Zimmer M, et al. Silencing of LASP-1 influences zyxin localization, inhibits proliferation and reduces migration in breast cancer cells. Exp Cell Res. 2006;312(7):97482. https://doi.org/10.1016/j.yexcr.2005.12.016

42. Lin YH, Park Z-Y, Lin D, Brahmbhatt AA, Rio M-C, Yates JR, et al. Regulation of cell migration and survival by focal adhesion targeting of Lasp-1. J Cell Biol. 2004;165(3):421-32. https://doi.org/10.1083/jcb.200311045.

43. Spiegel S, English D, Milstien S. Sphingosine 1-phosphate signaling: providing cells with a sense of direction. Trends Cell Biol. 2002;12(5):236-42. https://doi.org/10.1016/S0962-8924(02)02277-8.

44. Kassmer SH, Rodriguez D, Langenbacher AD, Bui C, De Tomaso AW. Migration of germline progenitor cells is directed by sphingosine-1phosphate signalling in a basal chordate. Nat Commun. 2015;6(1):8565. https://doi.org/10.1038/ncomms9565.

45. Jeffery WR, Gorički Š. Apoptosis is a generator of Wnt-dependent regeneration and homeostatic cell renewal in the ascidian Ciona. Biol Open. 2021;10:bio058526.

46. Jeffery WR. Distal regeneration involves the age dependent activity of branchial sac stem cells in the ascidian Ciona intestinalis. Regeneration (Oxf). 2015;2(1):1-18. https://doi.org/10.1002/reg2.26. 
47. Auger H, Sasakura Y, Joly J-S, Jeffery WR. Regeneration of oral siphon pigment organs in the ascidian Ciona intestinalis. Dev Biol. 2010;339(2):37489. https://doi.org/10.1016/j.ydbio.2009.12.040.

48. Jeffery WR. Regeneration, stem cells, and aging in the tunicate Ciona: insights from the Oral siphon. Int Rev Cell Mol Biol. 2015;319:255-82. https://doi.org/10.1016/bs.ircmb.2015.06.005.

49. Jeffery WR. Progenitor targeting by adult stem cells in Ciona homeostasis, injury, and regeneration. Dev Biol. 2019;448(2):279-90. https://doi.org/10.101 6/j.ydbio.2018.09.005

50. Tiozzo S, Ballarin L, Burighel P, Zaniolo G. Programmed cell death in vegetative development: apoptosis during the colonial life cycle of the ascidian Botryllus schlosseri. Tissue Cell. 2006;38(3):193-201. https://doi.org/1 0.1016/j.tice.2006.02.003.

51. Franchi N, Ballin F, Manni L, Schiavon F, Basso G, Ballarin L. Recurrent phagocytosis-induced apoptosis in the cyclical generation change of the compound ascidian Botryllus schlosseri. Dev Comp Immunol. 2016;62:8-16. https://doi.org/10.1016/j.dci.2016.04.011

52. Ballarin L, Schiavon F, Manni L. Natural apoptosis during the blastogenetic cycle of the colonial ascidian Botryllus schlosseri: a morphological analysis. Zool Sci. 2010;27(2):96-102. https://doi.org/10.2108/zsj.27.96.

53. Manni L, Zaniolo G, Cima F, Burighel P, Ballarin L. Botryllus schlosseri: a model ascidian for the study of asexual reproduction. Dev Dyn. 2007;236(2): 335-52. https://doi.org/10.1002/dvdy.21037.

54. Voskoboynik A, Weissman IL. Botryllus schlosseri, an emerging model for the study of aging, stem cells, and mechanisms of regeneration. Invertebr Reprod Dev. 2015;59(sup1):33-8. https://doi.org/10.1080/079242 59.2014.944673.

55. Zermati Y, Garrido C, Amsellem S, Fishelson S, Bouscary D, Valensi F, et al. Caspase activation is required for terminal erythroid differentiation. J Exp Med. 2001;193(2):247-54. https://doi.org/10.1084/jem.193.2.247.

56. Ishizaki Y, Jacobson MD, Raff MC. A role for caspases in lens fiber differentiation. J Cell Biol. 1998;140(1):153-8. https//doi.org/10.1083/jcb.140.1.153.

57. Ohsawa S, Hamada S, Kuida K, Yoshida H, Igaki T, Miura M. Maturation of the olfactory sensory neurons by Apaf-1/caspase-9-mediated caspase activity. Proc Natl Acad Sci U S A. 2010;107(30):13366-71. https://doi.org/1 0.1073/pnas.0910488107.

58. Denecker G, Ovaere P, Vandenabeele P, Declercq W. Caspase-14 reveals its secrets. J Cell Biol. 2008;180(3):451-8. https://doi.org/10.1083/jcb.200709098.

59. Kanuka H, Kuranaga E, Takemoto K, Hiratou T, Okano H, Miura M. Drosophila caspase transduces shaggy/GSK-3beta kinase activity in neural precursor development. EMBO J. 2005;24(21):3793-806. https://doi.org/10.1038/sj.emboj. 7600822.

60. Huang Q, Li F, Liu X, Li W, Shi W, Liu F-F, et al. Caspase 3-mediated stimulation of tumor cell repopulation during cancer radiotherapy. Nat Med. 2011;17(7):860-6. https://doi.org/10.1038/nm.2385.

61. Schulz MH, Zerbino DR, Vingron M, Birney E. Oases: robust de novo RNAseq assembly across the dynamic range of expression levels. Bioinformatics. 2012;28(8):1086-92. https://doi.org/10.1093/bioinformatics/bts094.

62. Grabherr MG, Haas BJ, Yassour M, Levin JZ, Thompson DA, Amit I, et al. Fulllength transcriptome assembly from RNA-Seq data without a reference genome. Nat Biotechnol. 2011;29(7):644-52. https://doi.org/10.1038/nbt.1 883.

63. Langmead B, Salzberg SL. Fast gapped-read alignment with bowtie 2. Nat Methods. 2012;9(4):357-9. https://doi.org/10.1038/nmeth.1923.

64. Li H, Handsaker B, Wysoker A, Fennell T, Ruan J, Homer N, et al. The sequence alignment/map format and SAMtools. Bioinformatics. 2009;25(16): 2078-9. https://doi.org/10.1093/bioinformatics/btp352.

65. Anders S, Pyl PT, Huber W. HTSeq--a Python framework to work with highthroughput sequencing data. Bioinformatics. 2015;31(2):166-9. https://doi. org/10.1093/bioinformatics/btu638.

66. Vizzini A, Pergolizzi M, Vazzana M, Salerno G, Di Sano C, Macaluso P, et al. FACIT collagen (1alpha-chain) is expressed by hemocytes and epidermis during the inflammatory response of the ascidian Ciona intestinalis. Dev Comp Immunol. 2008;32(6):682-92. https://doi.org/10.1016/j.dci.2007.10.006.

67. Christiaen L, Wagner E, Shi W, Levine M. Whole-mount in situ hybridization on sea squirt (Ciona intestinalis) embryos. Cold Spring Harb Protoc. 2009; 2009:pdb.prot5348.

\section{Publisher's Note}

Springer Nature remains neutral with regard to jurisdictional claims in published maps and institutional affiliations.

\section{Ready to submit your research? Choose BMC and benefit from:}

- fast, convenient online submission

- thorough peer review by experienced researchers in your field

- rapid publication on acceptance

- support for research data, including large and complex data types

- gold Open Access which fosters wider collaboration and increased citations

- maximum visibility for your research: over $100 \mathrm{M}$ website views per year

At BMC, research is always in progress.

Learn more biomedcentral.com/submissions 